\title{
Headache, depression and anxiety: associations in the Eurolight project
}

Christian Lampl ${ }^{1,2}$, Hallie Thomas ${ }^{3}$, Cristina Tassorelli,5, Zaza Katsarava ${ }^{6,7}$, Jose Miguel Laínez ${ }^{8}$, Michel Lantéri-Minet ${ }^{9,10}$, Daiva Rastenyte ${ }^{11}$, Elena Ruiz de la Torre ${ }^{12}$, Lars Jacob Stovner ${ }^{3,13}$, Colette Andrée $e^{14,15}$ and Timothy J. Steiner ${ }^{3,16^{*}}$

\begin{abstract}
Background: Headache disorders and psychiatric disorders are both common, while evidence, mostly pertaining to migraine, suggests they are comorbid more often than might be expected by chance. There are good reasons for establishing whether they are: symptoms of comorbid illnesses may summate synergistically; comorbidities hinder management, negatively influencing outcomes; high-level comorbidity indicates that, where one disease occurs, the other should be looked for. The Eurolight project gathered population-based data on these disorders from 6624 participants.
\end{abstract}

Methods: Eurolight was a cross-sectional survey sampling from the adult populations (18-65 years) of 10 EU countries. We used data from six. The questionnaire included headache-diagnostic questions based on ICHD-II, the Headache-Attributed Lost Time (HALT) questionnaire, and HADS for depression and anxiety. We estimated odds ratios (ORs) to show associations between migraine, tension-type headache $(\mathrm{TTH})$ or probable medication-overuse headache $(\mathrm{pMOH})$ and depression or anxiety.

Results: $\mathrm{pMOH}$ was most strongly associated with both psychiatric disorders: for depression, ORs (vs no headache) were $5.5[2.2-13.5](p<0.0001)$ in males, $5.5[2.9-10.5](p<0.0001)$ in females; for anxiety, ORs were 10.4 [4.9-21.8] $(p<0.0001)$ and 7.1 [4.5-11.2] $(p<0.0001)$. Migraine was also associated with both: for depression, ORs were 2.1 [1.3-3.4] $(p=0.002)$ and 1.8 [1.1-3.1] $(p=0.030)$; for anxiety 4.2 [2.8-6.3] $(p<0.0001)$ and $2.4[1.7-3.4](p<0.0001)$. TTH showed associations only with anxiety: ORs 2.5 [1.7-3.7] $(p<0.0001)$ for males, $1.5[1.1-2.1](p=0.021)$ for females. Participants with migraine carried $19.1 \%$ probability of comorbid anxiety, $6.9 \%$ of depression and $5.1 \%$ of both, higher than the representative general-population sample (14.3, 5.6 and $3.8 \%$ ). Probabilities in those with $\mathrm{MOH}$ were 38.8, 16.9 and $14.4 \%$; in $\mathrm{TH}$, they did not exceed those of the whole sample. Comorbid psychiatric disorder did not add to headache-attributed productive time losses, but weak associations existed $\left(R^{2}=0.020-0.082\right)$ for all headache types between lost productive time and probabilities of depression and, less so, anxiety.

Conclusion: In this large study we confirmed that depression and especially anxiety are comorbid more than by chance with migraine, and showed the same is true, but more strongly, with $\mathrm{MOH}$. Arguably, migraine patients and, more certainly, MOH patients should be screened with HADS in pursuit of best outcomes.

Keywords: Headache, Migraine, Tension-type headache, Medication-overuse headache, Depression, Anxiety, Comorbidity, Associations, Public health, Europe, Eurolight project, Global Campaign against Headache

\footnotetext{
* Correspondence: t.steiner@imperial.ac.uk

${ }^{3}$ Department of Neuroscience, Norwegian University of Science and

Technology, Edvard Griegs Gate, Trondheim, Norway

${ }^{16}$ Division of Brain Sciences, Imperial College London, London, UK

Full list of author information is available at the end of the article
} 


\section{Background}

Headache disorders are very common. In the Global Burden of Disease Study 2010 (GBD2010), tension-type headache (TTH) and migraine were found to be the second and third most prevalent disorders in the world [1]. Additionally, the group of disorders characterised by headache recurring on $\geq 15$ days/month affects $1.7-4 \%$ of the world's adult population [2], many of them having medication-overuse headache $(\mathrm{MOH})$ [3]. Headache disorders are also disabling: in GBD2013, they were revealed as the third cause of disability worldwide [4, 5], migraine and $\mathrm{MOH}$ being the substantial contributors. Also in GBD2013, depression and anxiety, both common psychiatric disorders, were ranked second and ninth highest causes of disability worldwide [4].

Common disorders occur together (are comorbid) by chance. Depression and anxiety are comorbid with each other more than by chance [6]. In addition, several studies point to a higher probability ( 2 to 4 times) of psychiatric disorders among people with migraine [7-12]. Few studies have specifically considered TTH, although people with episodic TTH were found no more likely than controls to experience anxiety or mood disorders [13], while those among a Chinese elderly population with chronic TTH were twice as likely to be suffering from depression [14]. There is evidence associating psychiatric morbidity with medication overuse [15], but no data on psychiatric comorbidity with $\mathrm{MOH}$ in the general population.

There are good reasons for wishing to establish whether or not there are associations between the common headache disorders and the common psychiatric disorders, all of them major contributors to public ill health and the burden of disability. The symptoms of comorbid illnesses are expected to summate synergistically. Comorbidities hinder management and negatively influence outcomes, more so when they are unrecognized. Comorbidity occurring more than by chance indicates that, where one disease occurs, the other should be looked for. It also suggests causal relationships or common aetiological factors, which should be elucidated.

The Eurolight project was an initiative supported by the European Commission Executive Agency for Health and Consumers (EHAC), and a partnership activity within the Global Campaign against Headache conducted by Lifting The Burden (LTB), a UK-registered non-governmental organization in official relations with the World Health Organization. Eurolight gathered data on these disorders from over 9000 variously-selected adult participants in a questionnaire-based crosssectional survey conducted in 10 countries in Europe [16]. The survey included demographic enquiry and screened for headache, depression and anxiety, with diagnostic questions for migraine, TTH and $\mathrm{MOH}$. We analysed the data for evidence of associations between depression and anxiety and headache type, by gender.

\section{Methods}

The methods of the Eurolight project have been described in detail elsewhere [17], and are summarised here.

\section{Ethics}

The National Ethics Committee of Luxembourg gave overall approval of the protocol and provisions for data protection. Further approvals were obtained from national and/or local ethics committees wherever needed as the methods for recruitment of participants differed between countries. In every country, prospective participants received written information explaining the project and its purpose.

\section{Project design and sampling}

Eurolight was a cross-sectional survey conducted from November 2008 to August 2009. It used modified cluster sampling in 10 countries which together represented $>60 \%$ of the adult population (18-65 years) of the European Union: Austria, France, Germany, Ireland, Italy, Lithuania, Luxembourg, Netherlands, Spain and United Kingdom (UK). The sampling methods varied between countries according to what was feasible, and are fully described elsewhere [17]. They are summarised in Table 1 for the six countries contributing to this analysis, which are those with samples drawn from the general population. In three other countries (Austria, France and UK), sampling was to some extent patient-based (although not headache patients), while additional samples from Spain and the Netherlands, and the only sample from Ireland, were recruited through patients' organisations [17]. None of these was included in this analysis because of the biases inherent in them.

\section{Instruments}

The survey used the same structured questionnaire in all countries [18], a derivative of LTB's HARDSHIP questionnaire developed for population-based surveys [19]. It was translated into the local languages following LTB's translation protocol for lay documents [20]. It had multiple parts. Demographic questions were followed by screening questions for headache and, in those screening positively, by headache-diagnostic questions based on ICHD-II [21]. The timeframe for enquiry was the preceding year. Participants identifying more than one headache type were asked to report only on the one that was most bothersome. Diagnoses were made by computerized algorithm [19]. The algorithm first identified, and separated, participants reporting headache on $\geq 15$ days/ month, of whom additional questions enquired into 
Table 1 Summary of data collection methods, and demographics of samples, in each country

\begin{tabular}{|c|c|c|c|c|c|}
\hline \multirow[t]{2}{*}{ Country } & \multirow[t]{2}{*}{ Sampling and data collection method } & \multirow{2}{*}{$\begin{array}{l}\text { Questionnaires } \\
\text { distributed and returned } \\
\mathrm{N} / \mathrm{n}\end{array}$} & \multirow[t]{2}{*}{ Gender } & \multirow[t]{2}{*}{$n$} & \multirow{2}{*}{$\begin{array}{l}\text { Age (years) } \\
\text { (mean } \pm \mathrm{SD})\end{array}$} \\
\hline & & & & & \\
\hline \multirow[t]{2}{*}{ Germany } & \multirow{2}{*}{$\begin{array}{l}\text { Random urban ( } 50 \%) \text { and rural }(50 \%) \text { samples aged } 18-65 \\
\text { years from general population listings supplied by local } \\
\text { municipal authority. Questionnaires distributed and returned } \\
\text { by post. No reminders sent. }\end{array}$} & \multirow[t]{2}{*}{$3000 / 318$} & M & 136 & $45.7 \pm 13.4$ \\
\hline & & & $\mathrm{F}$ & 182 & $43.8 \pm 11.8$ \\
\hline \multirow[t]{2}{*}{ Italy } & \multirow{2}{*}{$\begin{array}{l}\text { Random urban }(70 \%) \text { and rural }(30 \%) \text { samples drawn } \\
\text { from general population using listings supplied by Azienda } \\
\text { Sanitaria Locale of Pavia, stratified with regard to gender, } \\
\text { age (in range 18-65 years) and education. Questionnaires } \\
\text { distributed and returned by post. No reminders sent. }\end{array}$} & \multirow[t]{2}{*}{$3500 / 487$} & M & 203 & $44.9 \pm 12.9$ \\
\hline & & & $\mathrm{F}$ & 284 & $42.4 \pm 12.3$ \\
\hline \multirow[t]{2}{*}{ Lithuania } & \multirow{2}{*}{$\begin{array}{l}\text { Sample drawn from Kaunas city and Kaunas region using Residents' } \\
\text { Register Service, reflecting age (in range 18-65 years) and gender } \\
\text { composition of Lithuania and proportions living in rural (33\%) } \\
\text { or urban ( } 67 \% \text { ) areas. Data collection face-to-face, conducted by } \\
\text { medical students "cold-calling" door-to-door. }\end{array}$} & \multirow[t]{2}{*}{$1137 / 573$} & M & 237 & $39.8 \pm 14.0$ \\
\hline & & & $\mathrm{F}$ & 336 & $41.7 \pm 13.7$ \\
\hline \multirow[t]{2}{*}{ Luxemburg } & \multirow{2}{*}{$\begin{array}{l}\text { Sample aged 18-65 years, stratified for age, gender, region } \\
\text { and nationality, drawn from general population via national } \\
\text { social security registry (IGSS). Questionnaires distributed and } \\
\text { returned by post. Reminders sent one month later to non-responders. }\end{array}$} & \multirow[t]{2}{*}{$6498 / 1833$} & M & 769 & $40.8 \pm 12.8$ \\
\hline & & & $\mathrm{F}$ & 1064 & $40.3 \pm 12.6$ \\
\hline \multirow[t]{2}{*}{ Netherlands } & \multirow{2}{*}{$\begin{array}{l}\text { Survey conducted by market research company with access } \\
\text { to population sample of } 200,000 \text {, representative with regard } \\
\text { to gender, age (in range } 18-65 \text { years), region and education. } \\
\text { Questionnaire distributed by internet, to be completed on-line. } \\
\text { Study stopped when }>2000 \text { received back. }\end{array}$} & \multirow[t]{2}{*}{ unknown/2414 } & M & 1214 & $43.7 \pm 13.5$ \\
\hline & & & $\mathrm{F}$ & 1200 & $41.6 \pm 12.9$ \\
\hline \multirow[t]{2}{*}{ Spain } & \multirow{2}{*}{$\begin{array}{l}\text { Random sample of employees of companies operating in national } \\
\text { postal services in } 10 \text { areas of Spain, stratified to be representative } \\
\text { of general working population with regard to gender, age (in range } \\
18-65 \text { years) and education. Ten occupational health physicians delivered } \\
\text { and took return of questionnaires. One telephone reminder to non-responders. }\end{array}$} & \multirow[t]{2}{*}{ 1700/999 } & M & 410 & $44.1 \pm 11.9$ \\
\hline & & & $\mathrm{F}$ & 589 & $41.7 \pm 11.8$ \\
\hline \multirow[t]{3}{*}{ All } & & \multirow[t]{3}{*}{ unknown/6624 } & M & 2969 & $42.9 \pm 13.2$ \\
\hline & & & $\mathrm{F}$ & 3655 & $41.4 \pm 12.6$ \\
\hline & & & All & 6624 & $42.1 \pm 12.9$ \\
\hline
\end{tabular}

medication use. Probable $\mathrm{MOH}(\mathrm{pMOH})$ was diagnosed when (a) duration was typically $>4 \mathrm{~h}$ and (b) frequency of acute medication use was $\geq 15$ days/month and the medication was simple analgesics only, or $\geq 10$ days/ month when it was any other (compound analgesics, opioids, triptans and/or ergots). A diagnosis of $\mathrm{pMOH}$ trumped all other diagnoses. The remainder of this group were diagnosed as "other headache on $\geq 15$ days/ month". To all others (with headache on $<15$ days/ month), the algorithm applied ICHD-II criteria for migraine, TTH, probable migraine and probable TTH in that order. In the analyses, migraine and probable migraine were considered together, as were TTH and probable TTH $[22,23]$.

To enquire into impact, the questionnaire imported LTB's Headache-Attributed Lost Time (HALT) Index as a module. HALT captured lost productive time (days lost completely, and days of $<50 \%$ productivity) from paid and household work because of headache, and missed social and leisure activities [24]. In the analysis of HALT data, days of $<50 \%$ productivity were counted as and added to wholly lost days, being counterbalanced by days that were affected by headache but with productivity still $>50 \%$, which were ignored. Lost paid workdays and lost household workdays were summed separately, and then totalled for lost productive time.

To assess anxiety and depression among participants, the questionnaire imported, as a further module, the Hospital Anxiety and Depression Scale (HADS) [25]. This screening instrument was preferred to more specific instruments: firstly, it is easily applied in surveys of this type; secondly - and more importantly - it detects the subjective manifestations of anxiety and depression rather than somatic symptoms of distress [25], which, confoundingly, might include headache. HADS consists of two subscales, HADS-Anxiety (HADS-A) and HADS-Depression (HADS-D), each of seven items. In response to each item, participants report their subjective experience during the preceding week, rating it 0-3 (3 indicating maximum symptom severity). The sum of each subscale has a potential range of $0-21$. As recommended in the original description [25], we took a threshold of 11 on the respective subscale to indicate caseness for anxiety or depression. 


\section{Statistics}

Categorical variables are described in terms of frequency (n) and proportions (\%). Continuous variables are described in terms of means \pm standard deviations (SDs).

We calculated, as percentages with $95 \%$ confidence intervals (CIs), 1-year prevalences of migraine and TTH and point prevalences of $\mathrm{pMOH}$ and other headache on $\geq 15$ days/month in the participating sample, overall and by gender. We calculated point prevalences of depression and anxiety, and of comorbid depression plus anxiety, in the participating sample overall, by gender and by headache type. We performed logistic regressions, stratified by gender, in order to explore associations between all headache and headache types on the one hand and depression and anxiety on the other, taking the latter two as the dependent variables. We calculated odds ratios (ORs) with $95 \%$ CIs.

To establish whether depression or anxiety influenced the impact of headache on lost productive time, we did the following. For each headache type, we plotted headache-attributed lost time (measured by HALT and treated as continuous data) against HADS-D and HADS-A scores (also continuous data), and performed simple regression analyses, calculating $\mathrm{R}^{2}$ for the linear trendlines. We also conducted this analysis in reverse, with depression or anxiety rather than days lost as dependent variables.

We performed analyses using Microsoft Excel:mac 2011 software version 14.5.7.

\section{Results}

\section{Demographics}

Eurolight collected 9269 correctly completed questionnaires from all 10 countries, but the population-based sample from six countries included 6624 participants (males 2969 [44.8\%]; females 3655 [55.2\%]; mean age $42.1 \pm 12.9$ years) (Table 1 ).

\section{Prevalences}

The prevalences of each headache type in this sample, overall and by gender, are shown in Table 2. TTH (39.4\%) was the most prevalent headache type, but only a little more so than migraine (35.9\%). Both migraine (1.6:1) and pMOH (2.8:1), but not TTH (0.9:1) were more prevalent among females.
The prevalences of depression and anxiety, overall, by gender and by headache type (the last indicating comorbidities between these disorders), are shown in Table 3 . Anxiety in the total sample was 2.5 times more prevalent than depression. This ratio was reduced to $1.7: 1$ in the subsample with no headache. Both disorders were more prevalent among females: depression by a ratio of 1.2:1 $(p=0.0406)$, anxiety more so, by $1.8: 1 \quad(p<0.0001$; Fisher's exact test).

\section{Comorbidity}

Depression and anxiety were highly comorbid with each other in the total sample $(3.8 \%$ against an expectation of $0.8 \%$ from chance association alone).

In comparison with the total sample, depression and anxiety were each comorbid more than by chance with both migraine and pMOH but not with TTH or other headache on $\geq 15$ days/month. However, the lower part of Table 3 indicates that anxiety was more prevalent in those with any of the headache types than in those with no headache. Depression was more prevalent in all but other headache on $\geq 15$ days/month, although in TTH the excess was not significant. We confirmed these associations by calculating ORs, which are presented in Table 4. As predicted by the data in Table 3, the associations with $\mathrm{pMOH}$ were very strong. The analyses suggested that all associations, except that between depression and $\mathrm{pMOH}$, were stronger in males than in females.

To enquire into how comorbid depression or anxiety influenced the impact of headache on lost productive time, we plotted headache-attributed lost time (measured by HALT) against HADS-D and HADS-A scores. We did this for migraine, TTH and $\mathrm{pMOH}$, but found no influence when treating days lost as the dependent variable $\left(R^{2}\right.$ in the range $\left.0.0005-0.01\right)$. However, with the analyses reversed (depression and anxiety as dependent variables), weak influences were detected in all cases: most strongly between pMOH and depression $\left(R^{2}=0.082\right)$ and pMOH and anxiety $\left(R^{2}=0.059\right)$; next most strongly between TTH and depression $\left(R^{2}=0.036\right)$ and migraine and depression $\left(R^{2}=0.031\right)$, and least strongly between TTH and anxiety $\left(R^{2}=0.026\right)$ and migraine and anxiety $\left(R^{2}=\right.$ 0.020). The relationships with migraine are shown in Fig. 1 to illustrate.

Table 2 Prevalences of each headache type in the sample, overall and by gender

\begin{tabular}{lllll}
\hline Gender & \multicolumn{3}{l}{ Prevalences $(\%)[95 \% \mathrm{Cl}]$} & \\
\cline { 2 - 5 } & Migraine & Tension-type headache & Probable medication-overuse headache & Other headache on $\geq 15$ days/month \\
\hline All $(N=6624)$ & $35.9[34.7-37.1]$ & $39.4[38.2-40.6]$ & $3.0[2.6-3.4]$ & $2.5[2.1-2.9]$ \\
Male $(n=2969)$ & $26.9[25.3-28.5]$ & $41.6[39.8-43.4]$ & $1.5[1.1-1.9]$ & $2.6[2.0-3.2]$ \\
Female $(n=3655)$ & $43.1[41.5-44.7]$ & $37.7[36.1-39.3]$ & $4.2[3.5-4.9]$ & $2.3[1.8-2.8]$ \\
\hline
\end{tabular}


Table 3 Prevalences of depression and anxiety in the sample, overall, by gender and by headache type

\begin{tabular}{|c|c|c|c|}
\hline & \multicolumn{3}{|c|}{ Prevalences (\%) [95 \% Cl] } \\
\hline & Depression & Anxiety & Depression + anxiety \\
\hline All $(N=6624)$ & $5.6[5.0-6.2]$ & $14.3[13.7-15.1]$ & $3.8[3.3-4.3]$ \\
\hline \multicolumn{4}{|l|}{ Gender } \\
\hline Male $(n=2969)$ & $4.9[4.1-5.7]$ & $9.9[8.8-11.0]$ & $2.9[2.3-3.5]$ \\
\hline Female $(n=3655)$ & $6.1[5.3-6.9]$ & 17.8 [16.6-19.0] & $4.6[3.9-5.3]$ \\
\hline \multicolumn{4}{|l|}{ Headache type } \\
\hline No headache $(n=1271)$ & $3.5[2.5-4.5]$ & $6.1[4.8-7.4]$ & $1.7[1.0-2.4]$ \\
\hline Migraine $(n=2375)$ & $6.9[5.9-7.9]$ & $19.1[17.5-20.7]$ & $5.1[4.2-6.0]$ \\
\hline TTH $(n=2613)$ & $4.5[3.7-5.3]$ & $12.1[10.9-13.4]$ & $3.0[2.3-3.7]$ \\
\hline $\mathrm{pMOH}(n=201)$ & $16.9[11.7-22.1]$ & $38.8[32.1-45.5]$ & $14.4[9.5-19.3]$ \\
\hline Other headache on $\geq 15 \mathrm{~d} / \mathrm{m}(n=164)$ & $3.6[0.8-6.4]$ & $12.1[7.1-17.1]$ & $1.8[0-3.8]$ \\
\hline
\end{tabular}

$\pi \mathrm{H}$ tension-type headache, $\mathrm{pMOH}$ probable medication-overuse headache, $d / m$ days/month

\section{Discussion}

The key findings were (1) a confirmation that anxiety in particular, but also depression, are comorbid more than is expected by chance with migraine, and (2) first clear evidence of similar but stronger relationships with pMOH. Anxiety but not depression was weakly comorbid with TTH.

Before we comment further on these findings, we need to recall the limitations of the Eurolight study: the full study was not entirely population-based, sampling methods differed between countries [17], and participation rates were very low in some [16]. We were selective here, analysing data only from samples drawn from the general population, but even so we cannot argue that the estimates of prevalence that we made use of were reliable. Eurolight was a study of headache impact rather than prevalence [16], and this is no doubt reflected in the reported migraine prevalence of $35.9 \%$, which is much higher than the global and European means [1, $26]$ and only a little below that of TTH (39.4 \%). The reported prevalence of $\mathrm{pMOH}(3.0 \%)$ was also on the high side [3]. It was not, of course, a purpose of this study to report prevalences of headache types, but we draw attention at the outset to this potential source of bias.

As for the prevalence estimates for psychiatric disorders, we found that depression affected about one adult in 20 (5.6\%), while anxiety was almost three times as common (14.3\%). Both disorders were more prevalent in females, but this gender association was much stronger with anxiety. Recent reviews have estimated the global prevalence of depression in the range 4.4-5.0\% [27] and of anxiety in the range 4.8-10.9\% [28], with national studies generally finding these disorders to be more prevalent in developed Western countries [29, 30]. Therefore our estimates were in keeping with expectations, while towards their upper limits. It should be noted that HADS is a screening rather than diagnostic instrument for these disorders [25], with a tendency to underestimate prevalence of both [6]; we conclude, therefore, that levels of psychopathology in the sample, especially anxiety, were high. Depression and anxiety were highly comorbid with each other, as is invariably reported [6, 31].

We found, also, comorbidity at levels greater than expected by chance between each psychiatric disorder and each of migraine and pMOH. This, almost certainly, is the explanation of the high levels of psychopathology in our sample, especially since, on the psychiatric side, the associations were stronger with anxiety. On the headache side, the associations were strongest with pMOH, but still strong with migraine. Only anxiety showed an association with TTH, and this was weak. Eurolight diagnosed only the most bothersome headache type in participants reporting more than one [18, 22];

Table 4 Associations between headache types and depression and anxiety, by gender

\begin{tabular}{|c|c|c|c|c|c|c|c|c|}
\hline \multirow[t]{3}{*}{ Headache type } & \multicolumn{8}{|c|}{ Odds ratios $[95 \% \mathrm{Cl}]$ vs no headache as reference } \\
\hline & \multicolumn{4}{|l|}{ Depression } & \multicolumn{4}{|l|}{ Anxiety } \\
\hline & Males & $\mathrm{p}$ & Females & $\mathrm{p}$ & Males & $\mathrm{p}$ & Females & $\mathrm{p}$ \\
\hline Migraine & $2.1[1.3-3.4]$ & 0.002 & $1.8[1.1-3.1]$ & 0.030 & $4.2[2.8-6.3]$ & $<0.0001$ & $2.4[1.7-3.4]$ & $<0.0001$ \\
\hline Tension-type headache & $1.1[0.7-1.8]$ & 0.597 & $1.3[0.8-2.3]$ & 0.328 & $2.5[1.7-3.7]$ & $<0.0001$ & $1.5[1.1-2.1]$ & 0.021 \\
\hline Probable medication-overuse headache & $5.5[2.2-13.5]$ & $<0.0001$ & $5.5[2.9-10.5]$ & $<0.0001$ & $10.4[4.9-21.8]$ & $<0.0001$ & $7.1[4.5-11.2]$ & $<0.0001$ \\
\hline Other headache on $\geq 15$ days/month & $1.9[0.7-5.7]$ & 0.242 & $0.6[0.1-2.9]$ & 0.568 & $4.7[2.1-9.7]$ & 0.0001 & $1.3[0.6-2.6]$ & 0.474 \\
\hline
\end{tabular}



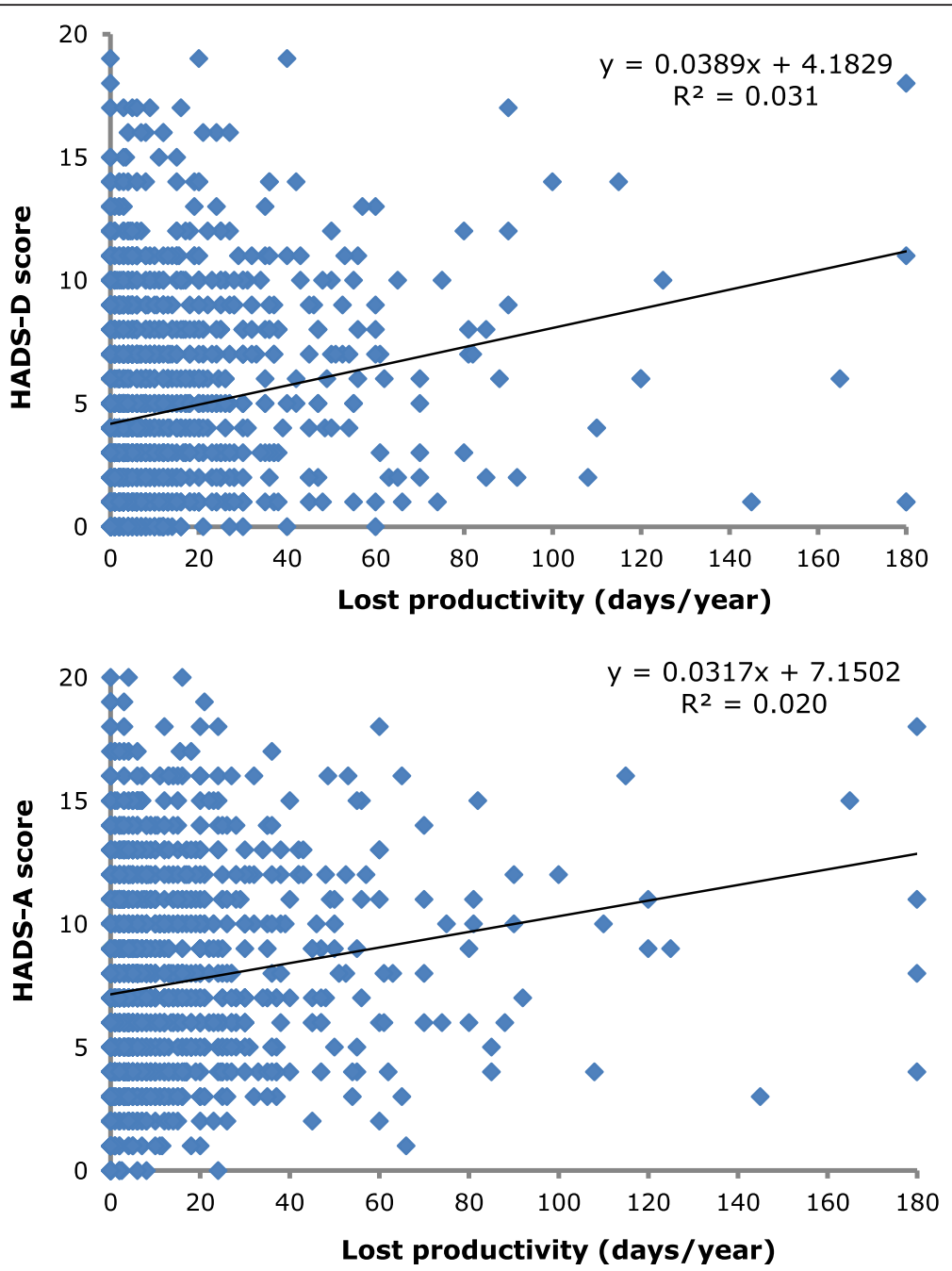

Fig. 1 Illustrative plots with linear trendlines of HADS-D score (top) and HADS-A score (bottom) against headache-attributed lost time in participants with migraine

most people with both migraine and TTH would describe the former as more bothersome and not report the latter. While the prevalence of TTH might as a result be underestimated [22], this could not have masked an association between depression and TTH uncomplicated by migraine.

Multiple studies have earlier found increased prevalences of depression and anxiety in people with migraine relative to those without headache [12, 32-34]. Migraine and anxiety are clearly comorbid, and several studies have demonstrated, as we did, that this association is stronger than that between migraine and depression [11, 35, 36]. However, relatively few population-based data exist on psychiatric comorbidity with TTH. Merikangas found no increased comorbidity between either depression or anxiety and TTH in a Swiss study [7]; we were almost in agreement with her. On the other hand, the very large Norwegian HUNT study found that both migraine and non-migrainous headache ( $80 \%$ of the latter being TTH) were comorbid with anxiety and depression (36).

For all headache types, these relationships became more pronounced with increasing headache frequency. The spectrum of highly-frequent headache (occurring on $\geq 15$ days/month) includes chronic migraine, chronic $\mathrm{TTH}$ and $\mathrm{MOH}$. Eurolight did not attempt to diagnose the first two, which cannot be done reliably in such surveys [22], but we found strong associations with pMOH: ORs of 5.5 for depression and 7-10 (greater in males) for anxiety. Until now, no population-based studies have specifically assessed psychiatric comorbidity with $\mathrm{MOH}$, although in clinical samples $\mathrm{MOH}$ patients frequently exhibit depression and anxiety [37]. It has also been shown that depression and anxiety are risk factors for developing $\mathrm{MOH}$ in migraineurs [38], so comorbidity is not surprising. Nevertheless, this study is the first to show it. 
Most of these associations showed some evidence of a gender-relationship, being stronger in males. Although individual differences were not significant, the consistency is striking. Victor et al., in a US study, observed that males with migraine were more likely than females with migraine to report anxiety or depressive symptoms compared with the same gender without headache [33]. However, a much earlier US study had found no gender difference in comorbidity between migraine and major depression or anxiety disorders [39]. If such a difference should exist, we would presume that the socioenvironmental and/or genetic factors explaining these comorbidities do not play exactly the same roles in males as in females.

On a clinical level, the importance of these associations is in how they might influence management. The key question is: should a physician treating a patient complaining of headache screen for comorbid psychiatric disorder? The data in the lower part of Table 3 indicate the probabilities of comorbid depression or anxiety by headache type, and are likely to be applicable to patients typically seen in primary care rather than those who have found their way to specialised clinics. A patient with migraine has a $19 \%$ probability of comorbid anxiety, almost $7 \%$ of depression and $5 \%$ of both. These are certainly higher, but not dramatically so, than the $14.3,5.6$ and $3.8 \%$ in the entire sample representative of the general population. On the other hand, comorbid psychiatric disorder, when present, adds to overall morbidity and, if not identified and itself treated, leads to unsuccessful headache management, or at least a poorer outcome. This suggests that, even in primary care where time is at a premium, there is a case for screening migraine patients with HADS. Against this it may be argued that, if anxiety - the more common comorbid disorder by a large margin - is actually secondary to the worrying headache symptoms that have brought the patient into a consultation, then treating the headache is the priority and perhaps all that is necessary. We have recently shown that interictal anxiety is an important component of the burden of migraine [40]. In a patient with $\mathrm{MOH}$, the probability of comorbid anxiety is almost $39 \%$, of depression $17 \%$ and of both $14 \%$, which make the case for screening with HADS considerably more compelling. In $\mathrm{TTH}$, the probabilities do not exceed those of the whole sample. In all cases, probabilities are higher in females than males, but this reflects the underlying prevalences of these disorders.

On a public-health level, our interest was more in how the effects of these comorbid disorders might summate. We assumed that a psychiatric disorder, when present, would add to overall morbidity and that this would be evident in the HALT analysis. We found, instead, that comorbid anxiety or depression did not add significantly to lost productive time attributable to headache. But there was a weak association - with all headache types, but most strongly $\mathrm{pMOH}$ - between lost productive time and the probability of depression or, less so, anxiety. We can speculate that this indicated cause: that comorbid anxiety and depression were at least in part the consequences of increasing lost productive time (or of the symptoms causing it), rather than due to underlying biological susceptibility. We have no further evidence in support of this idea.

While the Eurolight study had a number of methodological limitations, mentioned earlier, it also had several strengths. It was a European community-wide survey, sampling from ten countries [17], of which we took six (from west, north, east, central and south Europe) that provided population-based data. It used a validated questionnaire (HARDSHIP) diagnosing headache types by applying modified ICHD-II criteria algorithmically [19] and a widely accepted screening instrument (HADS) for psychiatric disorders [25]. It is, for the time being, the only source of population-based genderspecific data on psychiatric comorbidity with TTH and $\mathrm{MOH}$.

\section{Conclusion}

In this large cross-sectional European study, we confirmed that depression and especially anxiety are comorbid more than is expected by chance with migraine. We found the same, but more strongly, with $\mathrm{pMOH}$, and that anxiety but not depression is weakly comorbid with TTH. There is an arguable case for screening migraine patients with HADS, and a stronger case for $\mathrm{MOH}$ patients, in order to achieve best outcomes. Comorbid anxiety or depression did not add to lost productive time, but weak associations existed in all headache types between lost productive time and the probability of depression or, less so, anxiety.

\section{Competing interest}

TJS, ZK and LJS are directors and trustees of Lifting The Burden. The authors declare that they have no competing interests.

\section{Authors' contributions}

$\mathrm{CL}, \mathrm{CT}$ and TJS conceived the idea for this analysis. CA was Eurolight project leader. CA, ZK, JML, CL, ML-M, DR, ERdIT and CT contributed to data acquisition. Analysis and data interpretation were performed by HT, TJS, CL, CT and LJS. The article was drafted by CL with input from TJS, CT and LJS. All authors reviewed and approved the final manuscript.

\section{Acknowledgements}

Part-funding for this study was received from the European Agency for Health and Consumers of the European Commission. Financial support was also provided by Lifting The Burden, a UK-registered non-governmental organization conducting the Global Campaign against Headache in official relations with the World Health Organization.

We are grateful to the members of the Eurolight Project External Evaluation Board: F Antonaci, H Kettinen, P Sàndor, J Schoenen; to the Eurolight Project's Associated Partners: A MacGregor, G Mick, Asociacion Española de Pacientes con Cefalea, Migraine Action (UK), Migraine Association of Ireland, Nederlandse Vereniging van Hoofdpijnpatienten, European Headache Alliance, European Headache Federation, Lifting The Burden; and to the 
Eurolight Project's Collaborating Partners: J Afra, M Allena, B Carugno, J-M Gérard, H Hauser, C Lucchina, G Nappi, Konventhospital Barmherzige Brüder (Linz, Austria), Neurology Group of the Spanish Society of Occupational Practitioners (AEMMT), Austrian Neurological Society (ÖGN), Finnish Migraine Association.

\section{Author details}

${ }^{1}$ Headache Medical Center, Linz, Austria. ${ }^{2}$ Department of Neurogeriatric Medicine and Remobilisation, Hospital of the Sisters of Charity, Linz, Austria.

${ }^{3}$ Department of Neuroscience, Norwegian University of Science and Technology, Edvard Griegs Gate, Trondheim, Norway. ${ }^{4}$ Headache Science Centre, C Mondino National Neurological Institute, Pavia, Italy. ${ }^{5}$ Department of Brain and Behavioural Sciences, University of Pavia, Pavia, Italy. ${ }^{6}$ Department of Neurology, University of Duisberg-Essen, Essen, Germany. ${ }^{7}$ Department of Neurology, Evangelical Hospital Unna, Unna, Germany. ${ }^{8}$ Department of Neurology, Hospital Clinico Universitario, University of Valencia, Valencia, Spain. ${ }^{9}$ Departement d'Evaluation et Traitement de la Douleur, Centre Hospitalo-Universitaire de Nice, Nice, France. ${ }^{10}$ INSERM/UdA, U1107, Neuro-Dol, Clermont-Ferrand, France. ${ }^{11}$ Lithuanian University of Health Sciences, Kaunas, Lithuania. ${ }^{12}$ Asociacion Española de Pacientes con Cefalea (AEPAC), Valencia, Spain. ${ }^{13}$ Norwegian Advisory Unit on Headache, St Olavs University Hospital, Trondheim, Norway. ${ }^{14}$ Department of Pharmaceutical Sciences, University of Basel, Basel, Switzerland. ${ }^{15}$ Department of Population Health, Luxembourg Institute of Health, Strassen, Luxembourg.

${ }^{16}$ Division of Brain Sciences, Imperial College London, London, UK.

Received: 10 March 2016 Accepted: 25 May 2016

Published online: 01 June 2016

\section{References}

1. Vos T, Flaxman AD, Naghavi M, Lozano R, Michaud C, Ezzati M, Shibuya K, Salomon JA, Abdalla S, Aboyans V, Abraham J, Ackerman I, Aggarwal R, Ahn SY, Ali MK, Alvarado M, Anderson HR, Anderson LM, Andrews KG, Atkinson C, Baddour LM, Bahalim AN, Barker-Collo S, Barrero LH, Bartels DH, Basáñez MG, Baxter A, Bell ML, Benjamin EJ, Bennett D et al (2012) Years lived with disability (YLDs) for 1160 sequelae of 289 diseases and injuries 1990-2010: a systematic analysis for the Global Burden of Disease Study 2010. Lancet 380: 2163-2196

2. Jensen R, Stovner $\amalg$ (2008) Epidemiology and comorbidity of headache Lancet Neurol 7:354-361

3. Westergaard ML, Hansen EH, Glümer C, Olesen J, Jensen RH (2014) Definitions of medication-overuse headache in population-based studies and their implications on prevalence estimates: a systematic review. Cephalalgia 34:409-425

4. Vos T, Barber RM, Bell B, Bertozzi-Villa A, Biryukov S, Bolliger I, Charlson F, Davis A, Degenhardt L, Dicker D, Duan L, Erskine H, Feigin VL, Ferrari AJ Fitzmaurice C, Fleming T, Graetz N, Guinovart C, Haagsma J, Hansen GM, Hanson SW, Heuton KR, Higashi H, Kassebaum N, Kyu H, Laurie E, Liang X, Lofgren K, Lozano R, MacIntyre MF et al (2015) Global, regional, and national incidence, prevalence, and years lived with disability for 301 acute and chronic diseases and injuries in 188 countries, 1990-2013: a systematic analysis for the Global Burden of Disease Study 2013. Lancet 386:743-800

5. Steiner TJ, Birbeck GL, Jensen RH, Katsarava Z, Stovner LJ, Martelletti $P$ (2015) Headache disorders are third cause of disability worldwide. J Headache Pain 16:58

6. Steel Z, Marnane C, Iranpour C, Chey T, Jackson JW, Patel V, Silove D (2014) The global prevalence of common mental disorders: a systematic review and meta-analysis 1980-2013. Int J Epidemiol 43:476-493

7. Merikangas KR, Stevens DE, Angst J (1994) Psychopathology and headache syndromes in the community. Headache 34:S17-22

8. Breslau N, Andreski P (1995) Migraine, personality, and psychiatric comorbidity. Headache 35:382-386

9. Juang KD, Wang SJ, Fuh JL, Lu SR, Su TP (2000) Comorbidity of depressive and anxiety disorders in chronic daily headache and its subtypes. Headache 40:818-823

10. Lake AE III, Rains JC, Penzien DB, Lipchik GL (2005) Headache and psychiatric comorbidity: Historical context, clinical implications, and research relevance. Headache 45:493-506

11. Hamelsky SW, Lipton RB (2006) Psychiatric comorbidity of migraine. Headache 46:1327-1333
12. Jette N, Patten S, Williams J, Becker W, Wiebe S (2008) Comorbidity of migraine and psychiatric disorders - A national population-based study. Headache 48:501-516

13. Merikangas KR, Merikangas JR, Angst J (1993) Headache syndromes and psychiatric disorders: association and familial transmission. J Psychiatr Res 27:197-210

14. Wang SJ, Fuh JL, Lu SR, Liu CY, Hsu LC, Wang PN, Liu HC (2000) Chronic daily headache in Chinese elderly: prevalence, risk factors, and biannual follow-up. Neurology 54:314-319

15. Radat F, Sakh D, Lutz G, El Amrani M, Ferreri M, Bousser MG (1999) Psychiatric comorbidity is related to headache induced by chronic substance use in migraineurs. Headache 39:477-480

16. Steiner TJ, Stovner LJ, Katsarava Z, Lainez JM, Lampl C, Lantéri-Minet M, Rastenyte D, Ruiz de la Torre E, Tassorelli C, Barré J, Andrée C (2014) The impact of headache in Europe: principal results of the Eurolight project. J Headache Pain 15:31

17. Andrée C, Stovner LJ, Steiner TJ, Barré J, Katsarava Z, Lainez JM, LantériMinet M, Mick G, Rastenyte D, Ruiz dela Torre E, Tassorelli C, Vriezen P, Lampl C (2011) The Eurolight project: the impact of primary headache disorders in Europe. Description of methods. J Headache Pain 12:541-549

18. Andrée C, Vaillant M, Barré J, Katsarava Z, Lainez JM, Lair ML, Lantéri-Minet M, Lampl C, Steiner TJ, Stovner LJ, Tassorelli C, Sándor PS (2010) Development and validation of the EUROLIGHT questionnaire to evaluate the burden of primary headache disorders in Europe. Cephalalgia 30:1082-1100

19. Steiner TJ, Gururaj G, Andrée C, Katsarava Z, Ayzenberg I, Yu S-Y, Al Jumah M, Tekle-Haimanot R, Birbeck GL, Herekar A, Linde M, Mbewe E, Manandhar K, Risal A, Jensen R, Queiroz LP, Scher Al, Wang SJ, Stovner LJ (2014) Diagnosis, prevalence estimation and burden measurement in population surveys of headache: presenting the HARDSHIP questionnaire. J Headache Pain 15:3

20. Peters M, Bertelote JM, Houchin C, Kandoura T, Steiner TJ (2007) Translation protocols. J Headache Pain 8(Suppl 1):S40-S47

21. Headache Classification Subcommittee of the International Headache Society (2004) The international classification of headache disorders: 2nd edition. Cephalalgia 24(Suppl 1):9-160

22. Stovner LJ, Al Jumah M, Birbeck GL, Gururaj G, Jensen R, Katsarava Z, Queiroz LP, Scher Al, Tekle-Haimanot R, Wang SJ, Steiner TJ (2014) The methodology of population surveys of headache prevalence, burden and cost: principles and recommendations from the global campaign against headache. J Headache Pain 15:5

23. Khil L, Straube A, Evers S, Berger K (2013) Change in intraindividual ICHD-II headache diagnosis over time: a follow-up of the DMKG headache study. Cephalalgia 33:25-33

24. Steiner TJ (2007) The HALT and HART indices. J Headache Pain 8(Suppl 1): 22-25

25. Zigmond AS, Snaith RP (1983) The hospital anxiety and depression scale Acta Psychiatr Scand 67:361-370

26. Stovner LJ, Hagen K, Jensen R, Katsarava Z, Lipton RB, Scher Al, Steiner TJ, Zwart J-A (2007) The global burden of headache: a documentation of headache prevalence and disability worldwide. Cephalalgia 27:193-210

27. Ferrari AJ, Somerville AJ, Baxter AJ, Norman R, Patten SB, Vos T, Whiteford HA (2013) Global variation in the prevalence and incidence of major depressive disorder: a systematic review of the epidemiological literature. Psychol Med 43:471-481

28. Baxter AJ, Scott KM, Vos T, Whiteford HA (2013) Global prevalence of anxiety disorders: a systematic review and meta-regression. Psychol Med 43: 897-910

29. Kessler RC, Aguilar-Gaxiola S, Alonso J, Chatterii S, Lee S, Ormel J, Ustün TB, Wang PS (2009) The global burden of mental disorders: an update from the WHO World Mental Health (WMH) surveys. Epidemiol Psichiatr Soc 18:23-33

30. Bromet E, Andrade LH, Hwang I, Sampson NA, Alonso J, de Girolamo G, de Graaf R, Demyttenaere K, Hu C, Iwata N, Karam AN, Kaur J, Kostyuchenko S, Lépine JP, Levinson D, Matschinger H, Mora ME, Browne MO, Posada-Villa J, Viana MC, Williams DR, Kessler RC (2011) Cross-national epidemiology of DSM-IV major depressive episode. BMC Med 9:90

31. Kessler RC, Chiu WT, Demler O, Merikangas KR, Walters EE (2005) Prevalence, severity, and comorbidity of 12-month DSM-IV disorders in the National Comorbidity Survey Replication. Arch Gen Psychiatry 62:617-627

32. Radat F, Swendsen J (2005) Psychiatric comorbidity in migraine: a review. Cephalalgia 25:165-178 
33. Victor TW, Hu X, Campbell J, White RE, Buse DC, Lipton RB (2010) Association between migraine, anxiety and depression. Cephalalgia 30:567-575

34. Modgill G, Jette N, Li Wang J, Becker WJ, Patten SB (2012) A populationbased longitudinal community study of major depression and migraine. Headache 52:422-432

35. Lantéri-Minet M, Radat F, Chautard MH, Lucas C (2005) Anxiety and depression associated with migraine: influence on migraine subjects' disability and quality of life, and acute migraine management. Pain 118 319-326

36. Zwart JA, Dyb G, Hagen K, Odegard KJ, Dahl AA, Bovim G, Stovner $\sqcup$ (2003) Depression and anxiety disorders associated with headache frequency. The Nord-Trøndelag Health Study. Eur I Neurol 10:147-152

37. Heckman BD, Holroyd KA (2006) Tension-type headache and psychiatric comorbidity. Curr Pain Headache Rep 10:439-447

38. Hagen K, Linde M, Steiner TJ, Stovner LJ, Zwart JA (2012) Risk factors for medication-overuse headache: an 11-year follow-up study. The NordTrøndelag Health Studies. Pain 153:56-61

39. Breslau N, Davis GC (1993) Migraine, physical health and psychiatric disorder: a prospective epidemiologic study in young adults. J Psychiatr Res 27:211-221

40. Lampl C, Thomas H, Stovner L, Tassorelli C, Katsarava Z, Laínez JM, LantériMinet M, Rastenyte D, Ruiz de la Torre E, Andrée C, Steiner TJ (2016) Interictal burden attributable to episodic headache: findings from the Eurolight project. J Headache Pain 17:9

\section{Submit your manuscript to a SpringerOpen ${ }^{\odot}$ journal and benefit from:}

- Convenient online submission

- Rigorous peer review

- Immediate publication on acceptance

- Open access: articles freely available online

High visibility within the field

Retaining the copyright to your article

Submit your next manuscript at $\gg$ springeropen.com 